\title{
The Social Perspective Taking Process: Strategies and Sources of Evidence in Taking Another's Perspective
}

\section{Citation}

Gehlbach, H., \& Brinkworth, M. E. (2012). The social perspective taking process: Strategies and sources of evidence in taking another's perspective. Teachers College Record, 114(1), 226-254.

\section{Permanent link}

http://nrs.harvard.edu/urn-3:HUL.InstRepos:11393842

\section{Terms of Use}

This article was downloaded from Harvard University's DASH repository, and is made available under the terms and conditions applicable to Open Access Policy Articles, as set forth at http:// nrs.harvard.edu/urn-3:HUL.InstRepos:dash.current.terms-of-use\#OAP

\section{Share Your Story}

The Harvard community has made this article openly available.

Please share how this access benefits you. Submit a story.

\section{Accessibility}


The Social Perspective Taking Process:

Strategies and Sources of Evidence in Taking Another's Perspective

Manuscript submitted February 12, 2010

Revision submitted September 22, 2010

Running Head: SOCIAL PERSPECTIVE TAKING PROCESS 


\section{Cover Page:}

Hunter Gehlbach

Hunter_Gehlbach@gse.harvard.edu

(617) 496-7318

328 Longfellow Hall

13 Appian Way

Cambridge, MA 02138

Hunter Gehlbach is an assistant professor at Harvard's Graduate School of Education. His primary interests lie in using social psychological principles and research to improve schools. He also maintains an active research interest in how to most effectively design questionnaires. Recent publications include "Motivated thinkers and the mistakes they make” in Advances in motivation and achievement: Social psychological perspectives (with Maureen Brinkworth) and an article in Educational Psychology Review entitled "The social side of school: Why teachers need social psychology."

Maureen E. Brinkworth meb308@mail.harvard.edu (617) 945-1526

Maureen Brinkworth is a doctoral candidate at Harvard's Graduate School of Education. She is interested in how social perspective taking impacts different aspects of secondary classrooms - particularly the relationships between teachers and students. Her recent work includes "Motivated thinkers and the mistakes they make" in Advances in motivation and achievement: Social psychological perspectives (with Hunter Gehlbach).

\section{Brief article description}

Social perspective taking - the motivation and ability for individuals to discern the thoughts and feelings of others - is an important aptitude for numerous valued outcomes in schools. Yet, little is known about how people engage in this fundamental social process. This mixed-method study describes the strategies people use and the sources of evidence they rely upon when trying to take the perspective of others. 


\section{Structured Abstract}

\section{Background/Context:}

Research indicates that social perspective taking - the capacity to discern the thoughts and feelings of others - plays a role in many important outcomes in schools. Despite the potential benefits for students and educators, little is known about social perspective taking as a process.

Purpose/Research Question:

If educational researchers are ultimately to design interventions to help improve the perspective taking capacities of those in schools, they need to fully understand the underlying process, i.e., how social perspective taking actually happens. Particularly important is the need to understand: What strategies individuals use and what sources of evidence they draw from when they take the perspective of others?

Participants:

To investigate this question, a sample of 18 adults from an array of different professions (who were nominated as adept perspective takers) and 13 high school students (who were nominated as struggling with social perspective taking) participated in the study.

Research Design:

Participants completed in-depth interviews and a think-aloud protocol as part of this mixed-method, exploratory study. The interviews and think-alouds were coded for the type of social perspective taking strategy participants employed and for the sources of evidence they relied on, respectively.

Findings:

Results indicated that participants relied on 12 different types of SPT strategies and drew from seven different sources of evidence when discerning others' thoughts and feelings.

Conclusions/Recommendations:

These findings provide foundational knowledge that lays groundwork for ultimately developing approaches to teach social perspective taking. At a practical level, these findings provide options for students' and educators' to experiment with as they attempt to take the perspective of one another.

Keywords: social perspective taking, strategies, sources of evidence, social processes, social interaction 


\section{Executive Summary:}

More and more studies indicate that social perspective taking (SPT) - perceivers' motivation and ability to discern the thoughts and feelings of targets - is associated with a host of valuable outcomes. Many of these outcomes are of particular interest to those in schools - administrators, counselors, teachers, and students. Despite the growing scholarship in this area, researchers are just beginning to learn how the process of SPT actually unfolds. Gehlbach, Brinkworth, and Wang (this volume) have investigated the inception of the SPT process, i.e., what initially motivates people to engage in SPT. The current article serves as a companion article to that piece and extends the examination of SPT motivation to SPT ability. Specifically, this study explores the following research questions:

1) What strategies do individuals employ in their SPT attempts?

2) What sources of evidence do individuals rely upon when taking the perspective of others?

In combination with the companion article, the goal of this line of research is to provide a knowledge-base from which scholars might begin to learn the best way to teach SPT to educators and students.

To investigate these important questions, we collected data from the same 18 adults and 13 high school students who participated in the companion study. The adults came from an array of professions which required them to use SPT in different ways in their positions; they were identified by nominators as likely to be adept perspective takers. By contrast, the students were nominated as struggling with SPT or were participants in a program designed to assist students with Asperger's symptoms. The goal of this sampling approach was to maximize heterogeneity with regard to participants’ developmental level of SPT, the range of settings in which they approached SPT tasks, and their SPT motivation and ability. Semi-structured interviews and a "think-aloud" protocol served as the primary sources of data. In the interviews, participants described situations in which they had engaged in SPT and reflected on SPT strategies they had employed in these different instances. For the think-aloud protocols, participants watched a video of two individuals having a conversation. As they watched the video, participants paused the 
playback periodically to identify what inferences they were drawing about each person's thoughts or feelings and what evidence provided the basis for those inferences. Interview transcripts from both data sources were coded for evidence of the SPT strategies that participant used and for the sources of evidence that they relied upon.

The interview data documented twelve SPT strategies. Seven of these strategies were ways in which perceivers made inferences about the SPT targets in question:

1) Analogy - perceivers tried to better understand the target by recalling a parallel situation from their own experience.

2) Compare/contrast - perceivers compared the target to themselves (i.e., perceiver-target comparison), “most people,” other members of the target's group, or him/herself (i.e., target-target comparison across situations).

3) Consider present context - perceivers tried to account for situational influences on the target.

4) Draw on background information - perceivers recalled past information about the target.

5) Projection/anchoring and adjusting - perceivers “put themselves in the target's shoes” and, in some instances, adjusted for differences between themselves and the target.

6) Reflection - perceivers ruminated about the target or discussed the target with a third party.

7) Stereotyping - perceivers used generalized schemas about people to try and understand targets.

Five of these strategies helped perceivers gather more information about the target:

8) Attention regulation - perceivers focused their attention or the target's attention to maximize communication.

9) Emotion regulation - perceivers regulated their own or targets' emotions.

10) Increasing modalities - perceivers sought more information about the target by expanding the number or types of communication channels.

11) Information extraction - perceivers elicited more information from the target directly (through asking questions) or indirectly. 
12) Open-mindedness - perceivers maintained an open mind or entertained multiple hypotheses about the target as a means to understanding their thoughts or feelings.

In the think-aloud procedure, participants relied upon seven sources of evidence that included auditory, visual, and perceiver-generated sources:

1) Conversational substance - perceivers attended to the content of what was said.

2) Ancillary conversational cues - perceivers attended to diction, paraverbal cues, and/or conversational patterns.

3) Facial expressions - perceivers "read" facial expressions of emotion.

4) Eye movement - perceivers focused on eye movement or direction (especially eye contact).

5) Body language - perceivers attended to the positioning, gestures, movement, and proximity of targets.

6) Own feelings - perceivers attended to their own thoughts or feelings as a source of insight into understanding the target.

7) Lack of expected reaction/behavior - perceivers noted when an expected behavior or reaction did not occur.

Beyond the main goal of documenting which strategies and sources of evidence perceivers use when engaged in the SPT process, the findings from this study signal some potential practical implications and directions for future research. For example, simply knowing the range of SPT strategies and sources of evidence should provide perceivers a broader menu of options for approaching any given SPT task. Thus, teaching these options to students and educators might enhance their SPT accuracy merely by giving them more ways to figure out others. Because this line of work strives to inform the teaching of SPT particularly in educational settings, two future research directions are especially important. First, future studies will want to disentangle which strategies and sources of evidence generally lend themselves to more accurate inferences about others. Second, our participants often used several strategies and sources of evidence at a time. Future research that can ascertain whether reliance on more strategies or more sources of evidence generally leads to greater SPT accuracy would also be crucial knowledge for the teaching 
of SPT. Given the quantity and severity of misunderstandings within schools and in society more broadly, further research on SPT within schools seems especially urgent. 


\section{The Social Perspective Taking Process:}

\section{Strategies and Sources of Evidence in Taking Another's Perspective}

Atticus Finch: If you just learn a single trick, Scout, you'll get along better with all kinds of folks. You never really understand a person until you consider things from his point of view... 'til you climb inside of his skin and walk around in it.

Older Scout: [narrating] One time Atticus said you never really knew a man until you stood in his shoes and walked around in them; just standin' on the Radley porch was enough.

(Pakula \& Mulligan, 1962)

Rather than walking around in his shoes (or skin), to take the perspective of Boo Radley, Scout simply stood on his porch. Her enactment of Atticus's advice illustrates a major challenge for investigators of social perspective taking (SPT). Like Atticus, researchers know that many benefits accrue from taking the perspective of others, but they know little about the processes through which individuals actually engage in SPT. A person cannot literally climb into another’s skin. Borrowing others' shoes to walk around in is unlikely to help. So what actually happens when people do these things metaphorically? What strategies do individuals use to understand others? What sources of evidence do people rely on when taking the perspective of others? Answering these questions is crucial to ultimately determining the best ways to teach people how to improve their SPT.

The SPT process encompasses perceivers discerning the thoughts, feelings, motivations, and point of view of targets, as well as trying to understand how these targets view the situation. Conceptualized as a multi-dimensional aptitude, SPT encompasses the ability to understand others accurately as well as the motivation to employ that ability (Gehlbach, 2004a). In other words, for successful perspective taking to occur, perceivers must be motivated to try to understand one or more targets, choose appropriate strategies to 
discern those targets, select suitable sources of evidence to enact those strategies, and make accurate inferences based upon those sources of evidence.

Previous research has documented multiple benefits of SPT. From reducing aggression (Richardson, Green, \& Lago, 1998) to enhancing learning (Bernieri, 1991), many of these benefits are central to the roles of different individuals within schools. Administrators must be able to anticipate the type of leadership style that will work for the different populations with whom they work. For school counselors to be effective, they need to understand what it is like for students to struggle with an array of issues even if they have never experienced those same struggles. To maximize student learning, teachers need to know which type of feedback will work best for which students under different situations. As school populations in this country diversify, students increasingly need to communicate, negotiate, and resolve conflicts with those from cultural and linguistic backgrounds that are quite different than their own.

Because SPT is integral to a myriad of social interactions within schools, learning how to facilitate this process and bolster the accuracy of people's inferences is a challenge with immense potential payoffs. Multiple benefits for younger students have been realized through social and emotional learning curricula (e.g., Brown, Jones, LaRusso, \& Aber, 2010), yet few have examined how we might further develop the social skills and social motivations of older students and educators. Although SPT holds tremendous promise for improving the social climate in schools, core aspects of SPT need to be better understood before scholars can teach individuals how to improve their perspective taking. In thinking specifically about SPT accuracy, researchers must first understand the types and range of strategies and sources of evidence that people actually use. Second, they must ascertain 
which of these strategies and sources of evidence are associated with more accurate SPT. Third, scholars need to know which ways of teaching SPT are most effective for different school populations (e.g., students, teachers, counselors, and administrators). In other words, teaching individuals to accurately take the perspective of others begins by ascertaining which strategies and sources of evidence perceivers are using as well which ones they could be using. As a companion piece to the examination of SPT motivation by Gehlbach, Brinkworth, and Wang (this volume), this article picks up the SPT process after perceivers have been motivated to engage in SPT to illuminate two basic aspects of the SPT process:

3) What strategies do individuals employ in their SPT attempts?

4) What sources of evidence do individuals rely upon when taking the perspective of others?

At a theoretical level, studying these previously uninvestigated aspects of the SPT process should illuminate the range of approaches individuals employ when engaging in SPT. At a practical level, greater knowledge about these two aspects of the SPT process - particularly in concert with knowledge of SPT motivation (Gehlbach, et al., this volume) - lays important groundwork for how to teach SPT.

Toward these ends, we review research related to SPT ability and sources of evidence to clarify how our study contributes important complementary knowledge to these subsets of the SPT literature. After describing our sample, and research methodology, we document and categorize the 12 strategies that our participants reported using when they engaged in different SPT episodes and the seven sources of evidence they relied upon during a pair of SPT episodes. Our discussion of these two taxonomies 
focuses on the theoretical and practical importance of these strategies and sources of evidence in school settings as well as how this new knowledge about the SPT process might facilitate future research to promote SPT accuracy in schools.

\section{Key Facets of SPT Ability: Strategies and Sources of Evidence}

SPT is a broad construct with multiple factors impacting an individual's actual SPT performance in any given situation (see Gehlbach, 2004a for a review). SPT's influence on a host of outcomes for individuals within schools has also been reviewed elsewhere (see Gehlbach, et al., this volume, for an overview). Included in that overview is evidence that more accurate perspective takers learn more (Bernieri, 1991), get higher grades (Gehlbach, 2004b), experience fewer adjustment problems (Gleason, Jensen-Campbell, \& Ickes, 2009), and offer better support in close relationships (Verhofstadt, Buysse, Ickes, Davis, \& Devoldre, 2008). Thus, we narrow our examination of prior research on SPT to scholarship that specifically addresses SPT strategies and sources of evidence.

\section{SPT Strategies}

Past research has approached the study of SPT strategies in several ways: contrasting the efficacy of explicit SPT strategies, encouraging SPT through an experimental manipulation, and inferring strategy selection from participants' data. These approaches have simultaneously bolstered our understanding of SPT ability and raised questions about which strategies individuals can and do employ in different naturalistic settings. The present study is designed to complement the extant work on SPT ability by examining the strategies people actually use in their everyday lives. 
Some studies manipulate or contrast the strategies that participants are instructed to use. For example, Galinsky and Moskowitz (2000) asked participants to take the perspective of an individual in a photograph by responding to the prompt: "imagine a day in the life of this individual as if you were that person, looking at the world through his eyes and walking through the world in his shoes” (p. 711). Batson, Early, and Salvarani (1997) provided some subjects with explicit instructions to imagine how another feels while others were told to imagine how you would feel in that situation. In both studies, the authors found that different strategies led to different outcomes.

Other experiments do not direct participants to use particular SPT strategies. Vescio, Sechrist, and Paolucci designed a scenario in which participants listened to an African-American interviewee describing being a part of a negatively stereotyped group. They asked participants to "imagine how the person being interviewed feels about the experience he/she describes and how it has affected his/her life” (2003 p. 460). In a negotiation exercise, Drolet, Larrick, and Morris (1998) asked participants to think about the wants of their negotiation partner and estimate a price that would make him or her happy. In these examples, participants might use any number of different approaches to better understand their targets. This experimental approach parallels SPT in the real world in that participants retain substantial autonomy in how they engage in SPT. However, ascertaining the strategies employed by participants was not part of these research designs and which strategies participants actually used remains unknown.

Another approach, such as the one used by Ames (2004b) and Karniol (1986) is to use data to infer the types of SPT strategies used. Ames' participants predict their own mental states and those of a series of similar and dissimilar targets in different hypothetical 
situations. Based on the data gathered from these hypothetical situations, Ames infers that his participants employ strategies of projection and stereotyping depending upon the perceived similarity of the target. In a more open-ended approach, Karniol's (1986) sentence-completion procedure also used participant-generated data to infer SPT strategies. In her study, students filled in the blanks for sentences such as "When he saw , he

felt/thought because ” (p. 935). These sentence completions were then coded to develop a set of transformational rules. According to Karniol, these rules helped individuals to predict the psychological experience of others. These innovative approaches provide a third important avenue for examining SPT ability.

Each approach has enhanced the scholarly understanding SPT ability. However, because they occur in laboratory settings, it is unclear the extent to which these strategies represent those that people actually use in naturalistic settings. Furthermore, people may not only employ different strategies in different settings but may employ different combinations of strategies in different settings. Complementing these experimental approaches by identifying which SPT strategies people employ in the real world and understanding exactly how they are enacted will extend our knowledge in crucial ways. The present study establishes a preliminary taxonomy of the SPT strategies that individuals use in their everyday SPT attempts for these purposes.

\section{Sources of Evidence}

Research examining the sources of evidence that people rely upon in their SPT attempts abounds. Academics and professionals from applied fields writing for specialized journals and popular presses have addressed what types of inferences can be made from 
facial expressions, gestures, tone of voice, and eye contact. Despite the wealth of information, it is less clear which sources of evidence people actually use. In other words, given the near infinite number of choices of what particular aspects of a particular target in a particular context might be attended to, where do perceivers actually focus their attention?

Perhaps the best known academic work on different sources of evidence, is that of Paul Ekman and his colleagues' studies of facial expressions of emotion (Ekman, 1993; Ekman \& Friesen, 2003). They have created taxonomies involving hundreds of facial expressions of emotion, determined which muscles correspond to those emotions, and documented numerous guidelines to facilitate accurate emotion decoding. For example, they note that Duchenne (i.e., genuine) smiles can be differentiated from emblematic (i.e., fake) smiles by the presence of small wrinkles at the outside of the eyes.

In contrast, former Federal Bureau of Investigation agent, Joe Navarro (2008), claims facial expressions are actually among the more deceptive cues that might be used by perceivers. Instead, he advocates that perceivers use body language and gestures to gain insights into targets' thoughts, feelings, and motives. Among the many tips he describes, he notes that females tend to cover their suprasternal notch (the large dimple where the neck meets the chest) when they feel tense or uncomfortable.

These are but two cues from which perceivers can choose. For over 30 years the Journal of Nonverbal Behavior has published studies on "paralanguage, proxemics, facial expressions, eye contact, face-to-face interaction, and nonverbal emotional expression” ("Journal of Nonverbal Behavior," 2010). However, scholars still need knowledge regarding where people focus their attention when engaged in the SPT process. In other 
words, even if a perceiver mastered all the tips from Duchenne smiles to suprasternal notches and the collective wisdom gleaned from 30 years of journal articles, it seems impossible that s/he might be enact them all simultaneously while perceiving (and possibly interacting with) a target. Thus, despite the volumes of scholarship on what sources of evidence perceivers could use, given perceivers’ need for selective attention, knowing more about the sources of evidence they actually do use is an important, complementary line of inquiry. The present research begins addressing this question by having perceivers report on which sources of evidence they used while they are in the act of SPT.

\section{Methods}

The methodological approach employed in this study closely parallels the approach described in Gehlbach, et al. (this volume). To meet the study's goals of documenting and understanding the range of strategies and sources of evidence that people rely on in their SPT attempts, we used the same heterogeneous sample of perspective takers described in the companion study. We asked a different set of questions during the interview to learn about the SPT strategies that participants used. The present investigation also required an additional measure in which the researchers observed participants during a "think-aloud" procedure.

\section{Participants}

The same core tensions we faced in the companion study were present for this investigation. We had to balance our goal of documenting the range of strategies and sources of evidence as fully as possible with our goal of understanding these two important components of the SPT process in depth. Furthermore, we wanted to ensure that our 
findings would include strategies and sources of evidence representative of the type of SPT that would occur in schools.

We made three decisions in an effort to balance these competing goals. First, we purposefully sampled from both educators and high school students on the logic that, if we ultimately wanted this research to guide interventions for all individuals in schools, we would need data from both populations. This choice also gave us an opportunity to capture heterogeneity based on developmental level, given that SPT ability is thought to emerge at a sophisticated level during adolescence (Keating, 1990). Second, we chose not to limit our sample to only individuals within schools. Although we oversampled educators, we wanted to represent, as fully as possible, the range of strategies and sources of evidence that perceivers used. Moreover, schools ultimately need to educate students for all types of professions, so SPT interventions that are directed towards students will need to be based on research that is correspondingly broad. In addition to the educators in our sample, army interrogators, counseling psychologists, customs officials, police detectives, car salesmen, and a trial lawyer all participated. Third, we sampled individuals with a wide range of SPT abilities and motivations on the logic that more/less accurate and more/less motivated perceivers might employ different strategies and rely on different sources of evidence. Towards this end, we used nomination procedures to identify students who struggled with perspective taking (based on their teachers' and administrators' nominations) and adults who were particularly good at perspective taking (based on the nominations of supervisors and colleagues). To augment the heterogeneity of the sample, we also recruited a group of students who had been diagnosed with social anxiety and/or Asperger's-related symptoms. 
In the resultant sample, we interviewed and observed 13 high school students (11/13 male and 6/13 from the social anxiety/Asperger's program) and 18 adults (11 male). Participants were $74 \%$ White (62\% in the student sample and $88 \%$ in the adult sample), with African-Americans and Asians comprising the other races. The mean age was 43.4 years old for the adults ( $s d=11.5$ ) and 15.9 years old for the students $(s d=1.3)$.

\section{Measures}

Interview. To address investigate which types of SPT strategies individuals use, we conducted semi-structured interviews with our participants. Specifically, we asked them to, "think of a situation in which you tried to take another person's perspective and did a particularly good job” as well as a time when they did not do a particularly good job. (For the companion study, participants also described instances when they were particularly motivated/unmotivated to engage in SPT during these same interviews). To facilitate participants' recall, we frequently followed up with probes (e.g., What was the context/issue? Who was involved? What steps or strategies did you use to figure out their thoughts and feelings?).

Observations. To investigate the types of evidence that participants relied upon during an SPT episode, we observed participants as they engaged in a SPT task. These observations were modeled after "think-aloud" procedures used in survey methodology (e.g., Willis, 2005) by adapting a video task in which perceivers had to take the perspective of two people having a conversation (see Gehlbach, et al., this volume). Participants thought aloud for two of these videos. In the first, "Patti" and "Janet" discussed a disagreement that Janet had with her boyfriend; in the second, "Rosemary" told "Oscar" about an embarrassing moment Rosemary experienced during a lip-synching content. 
After seeing the whole video (2:25 minutes and 2:04 minutes, respectively), participants then re-watched the same video, pausing it each time that they had an insight or inference about the social interaction they saw. The researchers recorded the insights and inferences with a digital voice recorder, noting the time of each pause within the video. The recordings were transcribed and coded for the sources of evidence that participants relied upon while attempting to take the perspective of the two individuals in the video.

Data collection procedures. The data collection procedure mirrored the companion study. After identifying potential participants through the nomination procedures described above, we contacted the nominated individuals (and their parents in the case of minors). We met most participants on our university campus or at their school/place of work. The researchers guided participants through the completion of each measure. For most participants, the procedures lasted about two hours. Although most participants completed all measures, three individuals declined to be interviewed due to the sensitive nature of their work.

Interview coding procedures. All interviews and think-alouds were recorded and transcribed. To establish reliable coding systems, we followed essentially the same procedure as we used to develop the SPT motivation codes in the companion study. First, we listed a small number of codes hypothesized to be important based on a review of the literature. For example, initial codes included facial expressions of emotion (Ekman \& Friesen, 2003) as a source of evidence and stereotyping and projection (Ames, 2004a) as strategies. Next, two transcripts were selected and read by all coders for potential categories and subcategories of SPT motivations. A tentative set of codes was culled from the literature and these transcripts. For each code a definition, indicators of what 
characteristics should be present or absent, qualifications, exclusions, and examples were compiled into a preliminary codebook. Using this codebook, all coders completed a second round of coding on new transcripts. Information from this round led to minor revisions to the coding scheme. For the final coding, all transcripts were coded in small sets (roughly 3 transcripts) using these final codes. Within each set of transcripts, at least one transcript was coded by two coders and consensus was reached on any codes that differed.

We computed the reliability of the final coding process by comparing the codes identified by two coders for at least every third transcript. Agreement was calculated as follows ${ }^{1}$. We assigned a point each time that raters agreed in their coding of a certain segment of transcript. A zero was assigned for segments of transcript where a code was identified by only one coder (i.e., the other coder saw no codes) and where the same segment of transcript was coded differently by each coder. Agreement was computed by dividing the total number of codes where both raters agreed by the total number of codes assigned. The overall agreement for the SPT strategies was $91.3 \%$ and for sources of evidence was 90.6\%. Appendix A illustrates the coding process for the SPT strategies; Appendix B does the same for the think-aloud procedure.

\section{Results}

As described in the companion article, we wanted to establish that our sample was indeed heterogeneous with regard to participants SPT motivation and ability. The results of these analyses are detailed in Gehlbach et al. (this volume) - the full measures are presented in Appendix A and the results are presented in Table 1 of that article. We felt

\footnotetext{
${ }^{1}$ We computed agreement, rather than Cohen's Kappa, because there were no clear units into which the transcripts might be divided to compute the level of agreement that might occur by chance.
} 
comfortable that our sample did indeed represent a broad range of SPT aptitudes, and turn our focus to the SPT strategies and sources of evidence that those participants used.

\section{Social Perspective Taking Strategies}

Twelve separable SPT strategies emerged from the interviews. Although our participants often employed multiple strategies simultaneously, each strategy listed can occur independently from the others. Because perceivers’ self-reports of how well they did in a particular SPT instance are notoriously bad at predicting actual accuracy (Realo et al., 2003), we made no attempt to judge the efficacy of the strategies. Instead, we focused on the types of strategies used and have organized them into inferential strategies and information cultivation strategies. Inferential strategies are those in which participants attempted to make inferences from available information. By contrast, information cultivation strategies were attempts by perceivers to solicit more information about the target.

\section{Inferential strategies.}

Analogy. When using analogies, perceivers thought of a situation which was comparable to the one that the target was currently experiencing in some important way. Unlike “putting themselves in someone else’s shoes,” perceivers using this strategy projected themselves into or reminded themselves of a situation that paralleled the one that the target was experiencing. For example, one student participant was trying to relate to a friend who was being picked on at school and pressured by his parents. Rather than trying to imagine being picked on by peers or pressured by parents, he said, “I tried to remember if I've ever experienced things like that. Like being insulted or being under pressure. And I do get under a lot of pressure from some people, so I know how that feels... and I can 
imagine how that felt for him.” One potential advantage of this approach was illustrated by another participant. During high school, she had tried to take the perspective of a classmate who was struggling academically. Because she had excelled academically, trying to put herself in her friend's shoes probably would not have helped her truly understand his emotional state. Instead she recalled how she had felt in athletic contexts (where she felt less competent) and reported being better able to understand her friend through this approach.

Compare and contrast. A second strategy was to compare and contrast the target to different individuals or groups. Our participants used four comparison groups. First, perceivers would compare themselves to the target. In one illustration, after having her class observed, a teacher met with an administrator who was critical of the noise levels in her room. To try to figure out why the administrator focused on that particular issue, she hypothesized:

Maybe he's the kind of person who's only ever been able to work in complete silence. Maybe he grew up in a really quiet home, not with multiple brothers and sisters and so he isn't able to tune out noise. Maybe he's really sensitive to it and maybe I'm not. Maybe I'm desensitized to that kind of noise and chatter because I'm in a classroom every day and because I've just lived in noisy environments.

Second, perceivers compared targets against a generic person. In other words, they contrasted the target against how they imagined "most people" would act in that situation. Although related to the stereotyping strategy described below, perceivers using this strategy did not assume that target's thoughts or feelings would automatically fit a certain stereotype based on their gender, race, age or some other personal characteristic. Instead, perceivers explicitly processed target specific information and then compared that information to a pre-existing range of behavior that they had in mind. For instance, when 
working at a border crossing a customs official reported that he frequently contrasted the individual behavior of the passengers driving across the border with the typical behaviors he saw from travelers. When the individual behavior deviated from that of the "normal traveler," he followed up with more questions.

Third, some participants compared targets against other members of a group to which they belonged. As a prototypic example, one teacher described trying to infer whether a student comprehended the class material by comparing the student's blank stare against the facial expressions of his classmates. She judged that the more that his classmates appeared confused, the more likely it was that the particular student's blank stare was attributable to a lack of comprehension.

Fourth, almost as though they were conducting a within-subjects-experiment, our participants compared targets across different situations. In other words, perceivers compared a target's present behavior with past behaviors in other contexts as a way to infer what his/her thoughts and feelings might be. One student summarized this approach, "Usually, if they've been my friend for a while, I’ve probably memorized what they do when they're sad, mad, happy, etc. and so I can usually tell what they're feeling, and maybe even sometimes thinking."

Consider present context. Some participants weighed features of the present context and circumstances to try to get a sense of what situational factors were being experienced by the target. For example, in taking the perspective of one of her students, one teacher described how the boy's behavior was profoundly influenced by his surrounding social group. When he was coaching basketball to younger students, this boy was, "a brilliant coach. He was able to figure out what they needed, push the kids, he was 
just able to figure out where they were at." However, she continued, "as soon as he got around his friends he was acting like this big dope again.” Thus, when trying to take this particular student's perspective, the teacher focused on which other students inhabited his immediate context.

Draw on background information. Participants using this strategy searched their memories for relevant past information about the target in question. The information may have come from previous experiences with the target, observing the target, or what others have said about the target. In the aforementioned example (from the compare and contrast section) where the teacher tried to better understand her supervisor's perspective during their post-lesson debriefing, she went on to note that the supervisor, "grew up going to school in Taiwan, very rigid, very disciplined, very silent. And so it was really helpful for me to understand that this wasn't necessarily a personal attack, but that we were just coming from very different places.” Thus, pulling on what she knew about his background added important information into her assessment of why he had been critical of the noise in her classroom.

Projection/anchoring and adjusting. Some perceivers employed a projection strategy. When participants spoke about "putting themselves in somebody else's shoes” this was the strategy to which they referred. One student described using this strategy to understand his teacher after the teacher pulled him aside to tell him that he was disappointed about the student's grade in his class. The student explained:

I kinda just put myself in his shoes, like, tried to see the situation from his point of view, and I understood his frustration. I said, “if I were him, how would I feel about my performance?” And I knew myself that I didn't feel so great about how I was doing, so I knew that he wouldn't be very pleased about me. 
However, this strategy was not necessarily used in "pure” form. Participants often imaginatively projected themselves into the target's situation but then made adjustments based on known differences between themselves and the participant. This variation of the strategy can be thought of as an "anchoring and adjusting" approach in which perceivers anchor with their own experience and then make adjustments from that anchor (see Ames, 2004b; Epley, Keysar, Van Boven, \& Gilovich, 2004).

Reflection. Perceivers frequently reflected on a target as a SPT strategy after they had interacted with the target but were no longer in their presence. Some perceivers sifted through their memories about particular interactions to try and recall more details or see if alternative explanations came to mind. For instance, one student was trying to ascertain whether his soccer coach would start him or another player at goalie. He said he, "sat down, thought what I did well that practice, what I didn't do well... with the other person... what he did well and what he didn’t do well.” In contrast to this ruminative approach, some participants employed this strategy in a social way. They consulted with a third-party, often one who also knew the target, to debrief the interactions and possible interpretations of the target's behavior. In our sample, participants spoke with spouses, relatives, and friends in this debriefing capacity.

Stereotyping. Some participants used stereotyping as an SPT strategy. At the crudest level, this approach entailed guessing what most people of a certain group would think or feel in a particular situation. At more sophisticated levels, perceivers employed refined categories or schemas to make their predictions. For example, one of the teachers in the sample described how she tried to anticipate where conceptual challenges might lie 
in the lesson she was teaching. To do so, she thought about where most chemistry students tended to get tripped up due to their "non-analytical, sequential way of thinking."

\section{Information cultivation strategies.}

Attention regulation. When participants employed an attention regulation strategy, they would consciously focus their attention on the target or on a particular aspect of the target such as gestures or facial expressions. One of the psychologists noted that, for him, this was a particularly important part of the perspective taking process, "When I do a consultation, there is nobody else in the room but this person and myself and I'm just totally focused. I work very, very hard not only to listen to the words but to watch facial expressions.”

Emotion regulation. In some instances, participants employed emotion regulation strategies to facilitate collecting information about the target. For the most part, participants mentioned trying to calm themselves or otherwise trying to subdue intense, negative emotions (particularly anger). Many participants focused on regulating their own emotions. In a pronounced example of this approach one psychologist set aside additional time prior to meeting with a potentially challenging client. He explained, "what I try to do with people like this is, before they get there, to anticipate. When I know this guy's coming and I have a few minutes break before, I try to anticipate, 'OK, this is what's going to happen, or is liable to happen. Be on the alert for it."”

By contrast, some participants tried to regulate the target's emotions so that they could better read their thoughts and feelings. While working on a history project, one student used this strategy to facilitate working with a partner whom he had upset by being “too bossy". He anticipated that, while she was upset, his partner would minimize their 
time together and communication about the project. Because this reaction would make it harder for him to successfully read her and would damage their working relationship, he tried to regulate his partner's emotions in a more positive direction.

Increasing modalities. When using the strategy of increasing modalities, perceivers looked for ways to increase the channels of communication between themselves and their target. As perceivers shifted their communication modality from text to voice to visual, they collected more information from which to make inferences. For example, email provides words but no tone of voice, and a phone call provides intonation but no gestures. Several of our participants mentioned proactive (in anticipation of a complicated interaction) or reactive (for an interaction that was not going well) efforts to meet with targets face-to-face rather than continuing their interaction over email or phone. They felt that the greater number of open communication channels would enable them to read the other person more accurately. In fact, one participant indicated that she probably would have been better off had she spoken with her friend face to face:

Because I'm not very good talking on the phone, and I'm not really good with email. I feel like one of the reasons why I sometimes like email is because it's sort of vague and detached enough that there's room for interpretation. But at the same time, I feel like it doesn't necessarily convey what I can convey in person.

Occasionally, this strategy worked in unexpected ways. A customs official who was interviewing some travelers face-to-face could not get them to admit what their real names and countries of origin were until he allowed them to write down the information. In other words, the official got more information by offering an additional modality for communication even though it was a mode with fewer communication channels.

Information extraction. In its most obvious form, participants using an information extraction strategy simply asked targets what they were thinking or feeling. 
Although they frequently perceived this strategy to be quite effective, it is not always viable. For example, teachers cannot usually stop class to ask if one individual feels awkward or embarrassed in a room full of students. A more subtle form of this strategy that the psychologists employed was to float hypotheses past a target and allow for, but not demand a response. For example, one reported that she, "suggested a range of emotions that I would be feeling in this situation when she (the client) told me the circumstances. And just saw how she responded, and waited, and listened." A final manifestation of this strategy was also described by one of our psychologists. He sometimes engaged in, "selfdisclosure about how I'm currently feeling” in the hope that his targets might reciprocate by revealing information about how they were thinking or feeling.

Open-mindedness. Some participants made explicit efforts to keep an open mind and entertain multiple possibilities as to what the target might be thinking or feeling. This strategy to remain open-minded appeared to exist on a continuum. At the relatively passive end of the continuum participants often noted that they remained receptive to new ideas, hypotheses, or arguments relating to the target's perspective. At a more effortful level, they sometimes deliberately delayed or withheld judgment in order to remain open to new information before forming an opinion about the target's perspective. For instance, one of the psychologists said that she tried "to understand somebody's perspective and be non-judgmental about it.” She felt that this was a key ingredient in what made her successful as a therapist but also acknowledged that she struggled to implement this strategy with her in-laws! Perceivers who were especially active in their attempts to be open-minded generated multiple hypotheses to explain targets' behaviors and then assessed those hypotheses to determine the most plausible. As one student commented, "I 
try and think of all the reasons why they would do something, or all the things they would have thought about something, and I try to think of the one that fits them best.”

See Table 1 for a summary of these SPT strategies.

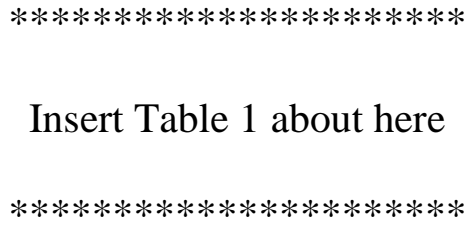

\section{Sources of Evidence for Social Perspective Taking}

During the think-aloud procedure, participants relied on seven different sources of evidence to make inferences about the thoughts and feelings of Janet, Patti, Rosemary, and Oscar. Two of these were auditory sources, three were visual, and two sources were generated by the perceivers themselves (i.e., rather than directly observable characteristics of the targets).

\section{Auditory}

Conversation substance. At some point, almost every participant referenced the actual content of what was being said as a key source of information. Participants often took the targets' words at face value. Other times, participants used the content of the conversation to make inferences about the targets’ perspectives. For example, one participant used conversational content to infer how Patti was reacting to Janet’s story about a misunderstanding between Janet and her boyfriend, "Well Patti seems to be sympathizing with Janet's boyfriend. She [Patti] says, 'but maybe he just, he just wanted to know' like she seemed to be seeing his [the boyfriend's] point of view."

Ancillary conversation cues. In using ancillary conversational cues, participants gleaned information from the target's conversational patterns, paraverbal cues, and word 
choices. For instance, one participant noted a change in the conversational pattern, "Patti cuts in and interrupts her [Janet] and says 'give an example'.” The participant inferred that Patti was challenging Janet by interrupting her in this way. Several participants relied on paraverbal cues when speculating that Rosemary was embarrassed when she laughed after describing an awkward experience. Another participant pointed out how he thought word choice conveyed how Janet was feeling,

Patti still is trying to offer up another perspective, which Janet acknowledges, but I don't think she [Janet] is particularly thoughtful about it. She [Janet] responds very, very quickly with a, "Yes, I know, but..." There's no- "Well, yeah, I could see it that way, now that you mention it." Nothing like that. It's "Yes, but..." and so I think for Janet, in that moment, she felt misunderstood by Patti.

\section{Visual.}

Facial expressions. Participants also relied on facial expressions to make inferences about the thoughts and feelings of the targets in the videos. One participant described how Rosemary's facial expression led him to infer that she was enthusiastic about the conversation. He explained, "You could see the big smile on her face, she's laughing, she’s ready to really keep going.” Another participant perceived Oscar’s facial expression as a sign that he might be confused, "He’s you know, almost seems very unsure about whether or not he should laugh, but looks rather soft, mouth open.”

Eye movement. Eye movement was another source of evidence that participants used as they engaged in SPT. They noted particular eye movements such as blinking, but perhaps most important was their observation of eye contact and lack of eye contact. For instance, one participant used different levels of eye contact to make inferences about Rosemary. She commented, "Rosemary seems to be pretty...overall a confident girl. She looks Oscar in the eyes quite a bit.” Later the participant commented, "I think she’s 
looking away a lot more. I think she’s really lost in her own story. She’s kind of talking up to the sky and gesturing up to the sky, rather than looking at him during the story.”

Body language. Our participants made inferences from four types of body language: positioning, gestures, movement, and proximity. In observing the targets’ positioning, they noted whether they were leaning forward or back, were upright or slouching, had crossed their legs or not, and so on. For example, one participant made several inferences about Patti and Janet based on positioning:

Janet's body posture - how she's slouched pretty far down on the chair and she has her arms crossed, it's just very, it is just a very interesting way for them to start off sort of facing each other. Patti is kind of leaning in, sitting up and Janet's almost as horizontal as she could be in a chair. To me, it already looks a little bit like, Janet's a little defensive and not really sure how much she wants to engage in this conversation with Patti. Patti seems at least a little bit more onboard.

The gestures participants made inferences from included nodding, shrugging, hand movements, and many others. One participant pointed out how Janet's gestures communicated that she was feeling "very, very frustrated and angry." She explained,

She [Janet] starts gesturing with her hands, which is one of the few times that she does it. Her hands have seemed pretty at rest besides the fidgeting. She hasn't picked them up off of her lap. Janet looks frustrated enough to be, again, almost re-living this, this moment of frustration. As she tells the story, she almost acts out, like moving her fingers as if she's typing.

Movement was relatively restricted given that the targets were seated for their conversations. Yet, participants still noted different movements made by the targets such as fidgeting or shifting in their chairs. For example, one participant noted that a target was “kinda moving around in her chair, which makes me think she’s a little nervous.” Participants also noted the targets' relative proximity to one another, such as when they leaned towards or away from each other. This was often used to infer interest in the conversation. For instance, one participant commented, "The other girl is sitting up and towards her...her body language is interested and listening.” 


\section{Perceiver generated.}

Own feelings. Some participants used their own feelings as a source of evidence. In other words, as they watched the videos, they monitored their own feelings and reactions and used that information as a data source from which to make inferences. For example, one participant felt uncomfortable with Patti's questioning and assumed that Janet must have felt similarly, “'just leave me alone right now'... that's what I'd say.”

Absence of expected reaction. Participants also noted the absence of an expected reaction as a source of evidence. For example, one participant inferred that Oscar was embarrassed for Rosemary because “he didn’t chuckle or smile” as the participant had expected when Rosemary told the punch line of an embarrassing story.

See Table 2 for a summary of these SPT sources of evidence.

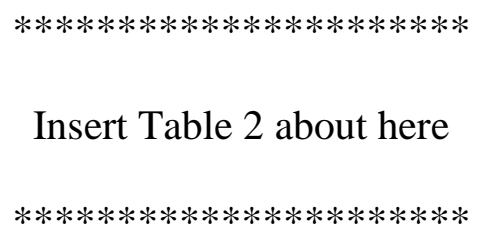

Table 3 provides a sense of how frequently the five most common strategies and sources of evidence were reported during the interviews and think aloud procedures. An examination of how the usage of these strategies and sources of evidence differed between the adults and the adolescents in the sample revealed no significant differences between the two populations that could not easily be accounted for by the number of significance tests conducted.

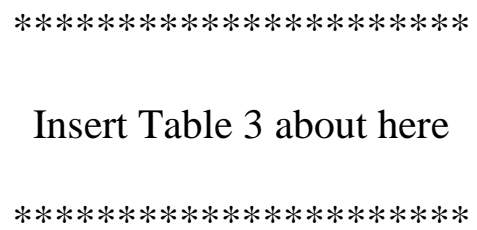




\section{Discussion}

This study is part of a larger research agenda whose ultimate goal is to teach individuals in schools how to improve their SPT ability. That SPT plays an important role in many education-related outcomes is well-documented. Thus, in combination with the companion investigation on SPT motivation, this study enriches our understanding of the SPT process. We anticipate that the findings will provide a foundation for learning which strategies and sources of evidence are associated with more accurate SPT. In turn, we hope that this knowledge will facilitate the teaching of SPT to different school populations including students, teachers, counselors, and administrators. While focusing particularly on school settings, we discuss how the two taxonomies that emerge from our investigation hint at some practical applications and suggest important future research directions.

\section{Practical New Knowledge from the Taxonomies}

Beyond the study's main purpose of documenting the SPT strategies and sources of evidence that people use, the main findings are suggestive of some practical implications. First, simply knowing the range of SPT strategies and sources of evidence should provide perceivers with a broader menu of options for approaching any given SPT task. Although some of the strategies and sources of evidence were expected and straightforward (e.g., asking a target how they felt as an information extraction approach or using facial expressions as a source of evidence), being reminded that these options exist, may help some students and educators improve their SPT accuracy. Specifically, some SPT strategies and sources of evidence may naturally work better for particular individuals. 
Thus, encouraging students and educators to experiment and figure out which SPT approaches work best for them may ultimately lead to more SPT accuracy.

Some findings ran counter to our intuitions and may provide ideas for novel SPT approaches. For example, increasing modalities was usually employed by increasing the number of communication channels between a perceiver and a target (e.g., shifting a conversation from email to face-to-face). However, in the instance where the customs official let travelers write down some background information, he garnered more information through a more restrictive communication modality. That one can acquire more information from a more restrictive communication channel is noteworthy for educational settings. This finding seems particularly relevant for teachers with shy students, i.e., they might offer these students alternate modalities for sharing their perspectives with their classmates. In addition, as online courses and communication forums proliferate, teachers need to better structure opportunities for students to learn from one another's disparate perspectives despite restrictive communication channels.

In addition to our findings illuminating more pathways or novel approaches to a given SPT task, the organization of each taxonomy also hints at some practical implications. For example, finding evidence for inferential and information cultivation strategies implies two different sub-processes that often occur in SPT episodes - an information gathering process and a synthesizing process whereby evidence and inferences based on that evidence are integrated. If future research confirms this structure, it could have important implications for school personnel. For instance, school administrators often need to facilitate SPT between different constituent groups within the school. Perhaps administrators could facilitate perspective taking between the groups by 
structuring ways for them to gather more information about one another's perspectives prior to making inferences.

The taxonomy of the sources of evidence offers another organizational distinction with potentially important practical implications. Specifically, the finding that people use themselves as a source of evidence in SPT episodes (e.g., by monitoring their own feelings and by noting the absence of expected reactions) helps to clarify how two people perceiving the same target often arrive at starkly different conclusions. Assuming this finding is supported by future research, teachers (e.g., in social studies classes) might use this information to their advantage. By having students read about historical figures from the same sources and then interview one another to solicit their peers' perspectives on the figure, students could be taught to see the importance role of their own experience and expectations as they try to understand others.

\section{Enabling Future Research}

The present investigation signals many important future research directions. In an attempt to prioritize which questions to pursue, we focus on two broad directions that seem especially likely to contribute to knowledge about how to best teach SPT in schools.

Which approach(es) work best? Our data offer few hints as to which strategies and sources of evidence are most likely to enhance our SPT accuracy. Presumably the strategy most likely to lead to SPT accuracy in any given situation will be a complicated interaction between the perceiver's cognitive abilities and motivation, characteristics of the target, how well the strategy was executed, and a host of cultural and situational factors. Likewise, the most reliable source of evidence in any given situation will depend upon some combination of the perceiver's abilities to perceive and decode certain types of 
evidence, how clearly the target presents those sources of evidence, and numerous contextual factors. Furthermore, the strategies and sources of evidence that work best for teachers (as they take the perspective of 30 students in a classroom simultaneously) might be quite different than those of a superintendent (who might be meeting with a local business leader while trying to balance the interests of the district's teachers, parents, and politicians). Ultimately scholars will want to clarify how these interactions operate.

However, of tremendous use to those interested in teaching SPT would be to know whether main effects exist such that certain strategies seem to work better in general. For example, the projection strategy seems to risk inaccuracies. When perceivers literally 'put themselves in someone else's shoes' they ignore cultural, personality, and affective differences (to name just a few) between themselves and the target. Thus, many individuals could rightly claim that they would have behaved differently had they been in someone else's shoes. Furthermore, in the anchoring and adjusting version of this strategy, we know that perceivers' adjustments tend to be insufficient (Epley, et al., 2004). Perhaps other strategies are more consistent in producing accurate inferences across most situations. Similarly certain sources of evidence might tend to be more reliable indicators for most people most of the time. These taxonomies provide a starting point for which strategies and sources of evidence future studies should begin comparing.

As a related investigation, scholars might test the possibility that SPT is better taught by allowing perceivers to engage in their usual SPT process and simply provide them with targeted feedback. Perhaps a combination of both teaching certain strategies and providing explicit feedback represents the optimal approach. Research that can help 
inform which pedagogical approach best facilitates the development of SPT ability will be immensely valuable.

Is more better? Our results indicated that many participants bundled strategies or used multiple sources of evidence simultaneously to make an inference. For example, the teacher who was critiqued by her administrator for the noise in her classroom developed multiple hypotheses as to why he was critical of the lesson, drew on background information she had about his upbringing in Taiwan, compared and contrasted her own upbringing to his, and later reflected on the interaction by debriefing with her mother. Participants combined sources of evidence during the think-aloud procedure in similar ways. Thus a particularly important question to investigate is whether the use of more strategies and combinations of sources of evidence generally lead to more accurate SPT. On the one hand, employing more strategies and attending to more sources of evidence would seem to provide the perceiver with more data and more ways to cross-validate tentative guesses as to a target's thoughts or feelings. On the other hand, if perceivers divide their attention across several strategies and sources of evidence the cognitive load may become too great, and degrade the caliber of the data that they collect, thus leading to less accurate inferences. Perhaps the real SPT skill that should be taught in schools is the dexterous employment of different strategies when faced with different sources of evidence in different contexts. Any emerging consensus on this question would be especially informative for teaching SPT.

\section{Limitations}

Several limitations may concern readers. As was acknowledged in the companion article, some may worry that participants could not have had sufficient insight into their 
own cognitive processes to report on their SPT habits during the interviews. Although this issue is of concern, as described in the companion article, we did structure the interviews and incorporate follow-up questioning to facilitate participants’ memory searches.

We also described in the companion article that this research represents an initial attempt at mapping the range of SPT strategies and sources of evidence; these categories will almost certainly undergo further refinement. Although our sample included a wide cross-section of individuals who reported on both extreme and mundane SPT episodes, it is possible that some strategies were not used or not reported by our participants.

Furthermore, although we did oversample educators, their total number remains small. Thus, it is possible that some strategies which are common to those contexts were not mentioned and thus are not included in our taxonomy.

A final issue revolves around the different forms of perspective taking that occurred in the interviews versus the think-aloud procedures. Specifically, participants in the interviews described a time when they tried to take the perspective of someone else. Most of the episodes described involved the participant in the role of a perceiver interacting with the SPT target. By contrast, the think-aloud procedure placed the participant in the role of an observer who could not interact with either of the SPT targets. Thus, it is possible that individuals would focus on different sources of evidence if they were directly involved in an interaction (or would choose different SPT strategies if they were merely observing). Furthermore, the think-aloud task involved watching normal, everyday conversations that were not based in school settings. Although normal, everyday conversations happen in schools quite frequently, it may be that other types of sources of evidence are relied upon by teachers when they are trying to take the perspective of a whole class of students or by 
students when listening to a teacher lecturing. As a result, the sources of evidence generated from this task may under-represent some of the sources of evidence that are relied upon in certain social interactions that are specific to schools.

\section{Conclusion}

Prior research shows that many psychological, social, and academic benefits may accrue from engaging in SPT. Meanwhile, within schools (and within society more broadly) no shortage of interpersonal misunderstandings exists between people. Thus, learning how to foster SPT aptitude for educators and students seems critically important. To the extent that educators can cultivate improved SPT as a norm, school communities will be poised to reap multiple benefits. However, for these benefits to be realized through wide-spread teaching of SPT, scholars must do more than encourage SPT through abstract metaphors like "climbing inside the skin of others and walking around in it." Researchers need to document concrete, specific aspects of the SPT process that allow us to make more accurate inferences about others. The SPT strategies and sources of evidence documented in this article represent an important step towards that goal. 


\section{References:}

Ames, D. (2004a). Inside the mind-reader's toolkit: Projection and stereotyping in mental state inference. Journal of Personality and Social Psychology, 87(3), 340-353.

Ames, D. (2004b). Strategies for social inference: A similarity contingency model of projection and stereotyping in attribute prevalence estimates. Journal of Personality and Social Psychology, 87(5), 573-585.

Batson, C. D., Early, S., \& Salvarani, G. (1997). Perspective taking: Imagining how another feels versus imagining how you would feel. Personality and Social Psychology Bulletin, 23(7), 751-758.

Bernieri, F. J. (1991). Interpersonal sensitivity in teaching interactions. Personality \& Social Psychology Bulletin, 17(1), 98-103.

Brown, J. L., Jones, S. M., LaRusso, M. D., \& Aber, J. L. (2010). Improving classroom quality: Teacher influences and experimental impacts of the 4rs program. Journal of Educational Psychology, 102(1), 153-167. doi: 10.1037/a0018160

Drolet, A., Larrick, R., \& Morris, M. W. (1998). Thinking of others: How perspective taking changes negotiators' aspirations and fairness perceptions as a function of negotiator relationships. Basic \& Applied Social Psychology, 20(1), 23-31.

Ekman, P. (1993). Facial expression and emotion. American Psychologist, 48(4), 384-392.

Ekman, P., \& Friesen, W. V. (2003). Unmasking the face: A guide to recognizing emotions from facial clues. Cambridge: Malor.

Epley, N., Keysar, B., Van Boven, L., \& Gilovich, T. (2004). Perspective taking as egocentric anchoring and adjustment. Journal of Personality and Social Psychology, 87(3), 327-339. 
Galinsky, A. D., \& Moskowitz, G. B. (2000). Perspective-taking: Decreasing stereotype expression, stereotype accessibility, and in-group favoritism. Journal of Personality and Social Psychology, 78(4), 708-724.

Gehlbach, H. (2004a). A new perspective on perspective taking: A multidimensional approach to conceptualizing an aptitude. Educational Psychology Review, 16(3), 207-234.

Gehlbach, H. (2004b). Social perspective taking: A facilitating aptitude for conflict resolution, historical empathy, and social studies achievement. Theory and Research in Social Education, 32(1), 39-55.

Gehlbach, H., Brinkworth, M. E., \& Wang, M.-T. (this volume). The social perspective taking process: What motivates individuals to take another's perspective? Teachers College Record.

Gleason, K. A., Jensen-Campbell, L. A., \& Ickes, W. (2009). The role of empathic accuracy in adolescents' peer relations and adjustment. Personality and Social Psychology Bulletin, 35(8), 997-1011.

Journal of Nonverbal Behavior. (2010) Retrieved January 26, 2009, from http://www.springer.com/psychology/personality+\&+social+psychology/journal/10 $\underline{919}$

Karniol, R. (1986). What will they think of next? Transformation rules used to predict other people's thoughts and feelings. Journal of Personality and Social Psychology, 51(5), 932-944. 
Keating, D. P. (1990). Adolescent thinking. In S. S. Feldman \& G. R. Elliott (Eds.), At the threshold: The developing adolescent. (pp. 54-89). Cambridge: Harvard University Press.

Navarro, J. (2008). What every body is saying. New York: Harper-Collins.

Pakula, A. J. (Producer), \& Mulligan, R. (Director). (1962). To kill a mockingbird [Motion picture]. USA: Universal.

Realo, A., Allik, J., Nolvak, A., Valk, R., Ruus, T., Schmidt, M., et al. (2003). Mindreading ability: Beliefs and performance. Journal of Research in Personality, 37(5), 420-445.

Richardson, D. R., Green, L. R., \& Lago, T. (1998). The relationship between perspectivetaking and nonaggressive responding in the face of an attack. Journal of Personality, 66(2), 235-256.

Verhofstadt, L. L., Buysse, A., Ickes, W., Davis, M., \& Devoldre, I. (2008). Support provision in marriage: The role of emotional similarity and empathic accuracy. Emotion, 8(6), 792-802.

Vescio, T. K., Sechrist, G. B., \& Paolucci, M. P. (2003). Perspective taking and prejudice reduction: The mediational role of empathy arousal and situational attributions. European Journal of Social Psychology, 33, 455-472.

Willis, G. B. (2005). Cognitive interviewing: A tool for improving questionnaire design. Thousand Oaks, Calif.: Sage Publications. 


\section{Acknowledgements}

This research was made possible through a generous grant from the William F. Milton Fund at Harvard University. The authors are extremely indebted to Cynthia Wang, Sophie Beran, and Dennis Lam, for their work on this project. The authors would like to thank Daniel Ames, Hilary Conklin, Mark Davis, Hahrie Han, and James Kim for their incisive comments on an earlier draft of this manuscript. 
Table 1: Taxonomy of social perspective taking strategies

\begin{tabular}{|c|c|}
\hline$\overline{\text { Strategy }}$ & Description \\
\hline Inferential Strategies & Perceivers use extant information to try to make inferences about the target \\
\hline Analogy & $\begin{array}{l}\text { Perceivers try to understand the target's experience by recalling a different situation from their own } \\
\text { experience that is presumed to parallel the target's situation. }\end{array}$ \\
\hline Compare/Contrast & $\begin{array}{l}\text { Perceivers use comparisons to identify differences and/or similarities that will aid in understanding the } \\
\text { target's thoughts/feelings. Specifically, perceivers can compare: } \\
\text { (1) themselves versus the target, } \\
\text { (2) "most people" versus the target, } \\
\text { (3) other members of the target's group versus the target, } \\
\text { (4) the target in the current situations versus the target in other situations. }\end{array}$ \\
\hline Consider Present Context & Perceivers evaluate the present context or the situational factors that the target is experiencing. \\
\hline $\begin{array}{l}\text { Draw on Background } \\
\text { Information }\end{array}$ & $\begin{array}{l}\text { Perceivers use information gathered from personal previous experiences with the target or from others' } \\
\text { reports about the target. }\end{array}$ \\
\hline $\begin{array}{l}\text { Projection/Anchoring \& } \\
\text { Adjusting }\end{array}$ & $\begin{array}{l}\text { Perceivers imagine themselves in the target's situation and may adjust for differences between } \\
\text { themselves and the target (i.e., perceivers "put themselves in the target’s shoes"). }\end{array}$ \\
\hline Reflection & $\begin{array}{l}\text { Perceivers reflect on the target and/or their interaction with the target through: } \\
\text { (1) searching their memories, recalling more details, and re-analyzing them (i.e., ruminate), or } \\
\text { (2) discussion with a third-party (i.e., conferring). }\end{array}$ \\
\hline Stereotyping & Perceivers use generalized schemas to infer targets' thoughts and feelings in a particular situation. \\
\hline
\end{tabular}


Information Cultivation Strategies Perceivers engage in regulatory or active behaviors to try to garner more information about the target

Attention Regulation

Emotion Regulation

Increasing Modalities

Information Extraction

Open-mindedness
Perceivers regulate their attention and/or the target's attention to maximize communication.

Perceivers may regulate their own or the target's emotions.

Perceivers seek more information about the target by increasing the number of communication modalities.

Perceivers elicit more information from the target about his or her thoughts/feelings.

Perceivers maintain an open-mind and/or entertain multiple hypotheses as to what the target is thinking or feeling. 
Table 2: Taxonomy of sources of evidence used in social perspective taking

\begin{tabular}{|c|c|}
\hline Source & Description \\
\hline \multicolumn{2}{|l|}{ Auditory } \\
\hline $\begin{array}{l}\text { Conversational } \\
\text { Substance }\end{array}$ & The actual content of what the target says \\
\hline $\begin{array}{l}\text { Ancillary Conversational } \\
\text { Cues }\end{array}$ & $\begin{array}{l}\text { Information gathered by the perceiver from cues in the target's speech, including: } \\
\text { (1) Diction - the target's choice of words or phrasing } \\
\text { (2) Paraverbal cues - nonverbal utterances, characteristics of (or changes in) the target's voice, or } \\
\text { how he or she delivers words } \\
\text { (3) Conversational patterns - the rhythm of the conversation and the target's engagement }\end{array}$ \\
\hline \multicolumn{2}{|l|}{ Visual } \\
\hline Facial Expressions & The emotions or psychological states that might be inferred from facial expressions \\
\hline Eye Movement & Eye movements (e.g., eye rolling or blinking) or direction (e.g., eye contact or direction of gaze) \\
\hline Body Language & $\begin{array}{l}\text { Characteristics of, or changes in, the target's body, including: } \\
\text { (1) Positioning (e.g., slouching, spreading out), } \\
\text { (2) Gestures (e.g., nodding, shrugging), } \\
\text { (3) Movement (e.g., fidgeting, tapping), } \\
\text { (4) Proximity (i.e., the target's position relative to another person) }\end{array}$ \\
\hline \multicolumn{2}{|l|}{ Perceiver generated } \\
\hline Own Feelings & $\begin{array}{l}\text { The perceiver's own physical or emotional reactions may be used as a source of information in } \\
\text { understanding the target's perspective }\end{array}$ \\
\hline $\begin{array}{l}\text { Lack of Expected } \\
\text { Reaction/Behavior }\end{array}$ & The absence of an expected behavior/reaction or a violation of specific expectations \\
\hline
\end{tabular}


SOCIAL PERSPECTIVE TAKING PROCESS 
Table 3. Frequency of five most commonly used strategies and sources of evidence

\begin{tabular}{|c|c|c|c|c|c|}
\hline Strategy & $\begin{array}{l}\text { Number of } \\
\text { people } \\
\text { mentioning the } \\
\text { strategy/source } \\
\text { of evidence } \\
\text { (out of 28) }\end{array}$ & $\begin{array}{c}\text { Total } \\
\text { frequency }\end{array}$ & $\begin{array}{l}\text { Mean number } \\
\text { of mentions } \\
\text { per person } \\
\quad \text { (out of 28) }\end{array}$ & SD & $\begin{array}{c}\text { Maximum } \\
\text { mentions by a } \\
\text { single person }\end{array}$ \\
\hline Information Extraction & 26 & 67 & 2.39 & 1.79 & 7 \\
\hline Compare/Contrast & 20 & 52 & 1.86 & 2.00 & 8 \\
\hline Draw on Background & 19 & 52 & 1.86 & 1.76 & 6 \\
\hline Open-mindedness & 17 & 32 & 1.14 & 1.48 & 7 \\
\hline Consider Present Context/Circumstances & 16 & 32 & 1.14 & 1.18 & 4 \\
\hline \multicolumn{6}{|l|}{ Evidence source } \\
\hline Ancillary Conversational Cues & 28 & 468 & 16.71 & 8.44 & 46 \\
\hline Body Language & 28 & 370 & 13.21 & 14.97 & 82 \\
\hline Conversational Substance & 26 & 197 & 7.05 & 4.67 & 20 \\
\hline Facial Expressions & 26 & 134 & 4.79 & 3.24 & 13 \\
\hline Eye Movement & 24 & 116 & 4.14 & 6.35 & 34 \\
\hline
\end{tabular}




\section{Appendix A: Sample SPT Strategy Coding}

\section{Interview Segment}

Participant: So, when understanding where kids get tripped up in Chemistry, um, you have to think like them, from a very non-analytical kind of sequential, way of thinking. (S) And that's not necessarily the way Chemistry works. And so, as I'm approaching something, I have to step back and look at what is the most, kind of in line way to think about this, andand where does that fail in this particular thing? Um, so I think that's part of it. I think just experience and we're helping kids through that is part of it.

Interviewer: And so you sort of make an effort to go back and re-think through Chemistry..

Participant: Yeah.

Interviewer: ....in this sort of linear fashion...

Participant: That's what I do in my plan.

Interviewer: ....as you understand them to be thinking through this.

Participant: That's right, that's right. So, when I plan I-, I deliberately think, where am I not going to be clear on this? Where are kids not going to understand this? Um, and I have to go back to that, where are they at developmentally? (B) At this point in time. Uhm, Chemistry is so, so visual and yet you can't see it so it's one of those things that's kind of tough for Sophomores to deal with at times. (S) Um, understanding kids I think is another part of it. Um, I, you know, I think I really make an effort to know individual kids and I think my school is particularly concerned about that and makes a lot of efforts to do that, uh. You know the way that $\mathrm{M}$ expresses that she doesn't understand something is very out there, she's comfortable saying I don't understand it, whereas other kids, uhm, they, you know, their body language starts to crush a little bit. They just start you know, playing with their hair, looking around, um things like that. (B, Cg)

\section{Three SPT Strategy Codes}

\section{Stereotyping (S)}

Definition: Using schemas about how people in certain situations generally present ${ }^{2}$.

Indicators: The target or situation is categorized first before other inferences are made about thoughts/feelings.

Qualifications/Exclusions: Does not include comparing the target to others only because they are present in the situation (e.g., if a student is staring at his feet and the teacher looks at the other students in the class to see if they are acting the same way).

\section{Draw on Background Information (B)}

Definition: Using information gathered about the target that is not part of the current situation.

Indicators: Using factual knowledge about, previous observations of, experiences with, or hearsay about the target to understand his/her thoughts/feelings

\footnotetext{
${ }^{2}$ For the sake of brevity, "present” was used instead of "think, feel, or act" throughout all of the codes.
} 
Qualifications/Exclusions: Does not include references to the target that draw on the current situation or comparisons made about the target across situations.

\section{Compare/Contrast (C)}

Definition: Using comparisons to identify differences and/or similarities that will aid in understanding the target's thoughts/feelings.

Group vs. Target (Cg)

Indicators: Comparing how the target seems to present to how other members of the target's group present.

Qualifications/Exclusions: The group is defined as the people in the target's immediate proximity not a categorization of the person. 


\section{Appendix B: Sample SPT Sources of Evidence Coding}

\section{Think-aloud transcript}

After viewing a portion of the video...

Participant: Janet has a kind of defensive posture. Umm, she's sitting with her arms crossed, kind of slouching, she seems kinda cranky at the start of it because of the way that she's sitting. (Bpo) Umm, she started with, "Well a-," so she's a little bit on the defense it feels like. (ACd) Uh... Patty seems to be genuinely engaged, and I think, umm, really thinking about it because she has- she has, umm, you know, asked the question, "Give me an example," which is a good question to have. (CS)

\section{Three SPT Sources of Evidence Codes}

\section{Body Language: Positioning (Bpo)}

Definition: Noting characteristics of or changes in the target's body positioning and stance.

Indicators: Posture (slouching, spread out, straight-up, etc.), closed /tight vs. loose/open Qualifications/Exclusions: Excludes movement mentioned in relation to the partner.

Ancillary Conversation Cues: Dictation (ACd)

Definition: Drawing on information conveyed by the target's choice of words and phrasing.

Indicators: Describing single words or phrases that the target chose to use.

Qualifications/Exclusions: May include information learned about the person over the course of the video.

\section{Conversational Substance (CS)}

Definition: Drawing on information conveyed in the content of the conversation.

Indicators: Quoting or paraphrasing what was said or saying the target "said it" to explain an inference

Qualifications/Exclusions: May include information learned about the person over the course of the video. 